Cómo citar este trabajo: Rubio Tenor, M., \& Ojeda-Rivera, J. F. (2018). Paisaje y paisajismo: realidad compleja y diálogos discursivos. Boletín de la Asociación de Geógrafos Españoles, 78, 245-269. doi: http://dx.doi.org/10.21138/bage.2436

\title{
Paisaje y paisajismo: \\ realidad compleja y diálogos discursivos
}

Landscape theory: complex reality and discursive dialogues

\author{
Marta Rubio Tenor \\ mrubten@upo.es \\ Juan Francisco Ojeda-Rivera \\ jfojeriv@upo.es \\ Departamento de Geografía, Historia y Filosofía \\ Universidad Pablo de Olavide (España)
}

\section{Resumen}

Este texto se plantea como un ejercicio que conduzca a una mejor comprensión del paisaje como realidad compleja y diálogo de discursos. Para ello, una sintética indagación en la trayectoria histórica de la configuración conceptual del paisaje y cultural del paisajismo mostrará cómo se ha ido gestando dicha complejidad a partir de momentos y paradigmas diferentes. También se comprobará en aquella misma indagación cómo se irán subrayando dos caracteres inseparables de la propia significación del paisaje: su diversidad epistemológica y su progresiva conformación como realidad dialéctica en la que se sintetizan dualidades y tensiones.

Palabras clave: paisaje; paisajismo; complejidad; patrimonio; recurso.

\begin{abstract}
This text is proposed as an exercise that leads to a better understanding of the concept of landscape as a complex reality and dialogue of discourses. To do this, a synthetic inquiry into the historical trajectory of the conceptual and cultural configuration of landscape will show how this complexity has been developed from different moments and paradigms. In this same inquiry, two inseparable
\end{abstract}


characteristics from the meaning of landscape will be emphasized: its epistemological diversity and its progressive conformation as a dialectical reality in which dualities and tensions are synthesized.

Key words: landscape; complexity; heritage; resource.

\section{Hacia un desvelamiento de la complejidad del paisaje}

Muchos autores - desde distintas disciplinas y en diferentes épocas - han reflexionado sobre el paisaje, que ha ido asumiendo en su consideración más común y compartida los caracteres axiomáticos de polisémico, híbrido y complejo. Precisamente el objetivo de este texto es mostrar cómo ha ido tejiéndose tal complejidad en una secular trayectoria de enmarañamiento conceptual, lingüístico, científico, metodológico, filosófico y estético y de comprensiones acumuladas.

Edgar Morin (1996, p. 32) dice que "a primera vista la complejidad es un tejido (complexus: lo que está tejido en conjunto) de constituyentes heterogéneos inseparablemente asociados. [...] La complejidad es, efectivamente, el tejido de eventos, acciones, interacciones, retroacciones, determinaciones, azares, que constituyen nuestro mundo fenoménico. Así es que se presenta con los rasgos inquietantes de lo enredado, de lo inextricable, del desorden, la ambigüedad, la incertidumbre [...]". El paisaje es el fruto de una urdimbre que debe ser comprendida en su propio enredo, porque la lectura simplemente analítica y disciplinaria de sus diferentes hilos tendería a su complicación más que a su comprensión compleja, ya que lo complicado (un motor de explosión, como artefacto mecánico) puede ser descompuesto para hacerlo inteligible, pero si se descompone lo complejo (el paisaje, como realidad trayectiva o medial entre lo objetivo y lo subjetivo) se corre el riesgo de no comprenderlo y de confundir sus partes con el conjunto que es más que el sumatorio de aquellas.

En efecto, la "combinación original" de elementos y patrones que constituye cualquier realidad compleja genera continuas "emergencias" a modo de nuevos caracteres e incluso nuevos entes que no existían entre los elementos y patrones previos ni por separado ni en su sumatorio. El paisaje - realidad compleja- no debe ser entendido, pues, como un mero sumatorio de relaciones entre elementos objetivos presentes en un lugar (ecosistema o espacio geográfico) o como las líneas, nodos, superficies y fronteras con que una comunidad de vivientes ha ido dibujando y convirtiendo en propio su espacio vital (territorio o país), sino que el paisaje es una especie de yingyang, una realidad trayectiva o medial, situada entre los elementos constitutivos de un lugar y las percepciones que se emocionan con ellos y producen posteriores emociones mediante imágenes o relatos de los mismos (Ojeda-Rivera \& Villa, 2016).

En tal marco de referencia, este texto se plantea como un ejercicio que conduzca a una mejor comprensión del carácter complejo del paisaje. Para ello, una sintética indagación en la trayectoria histórica de la configuración conceptual del paisaje y cultural del paisajismo nos mostrará -en 
primera instancia- cómo se ha ido gestando aquella complejidad, a partir de una serie de "momentos clave" de gran relevancia Asimismo, también resultará interesante comprobar en aquella misma indagación cómo se irán subrayando dos caracteres inseparables de la propia significación del paisaje: su amplitud y diversidad epistemológica, y su progresiva conformación tal que realidad dialéctica en la que se sintetizan dualidades y tensiones.

\section{Miradas diversas al origen del paisaje y del paisajismo}

Augustin Berque, que investiga el paisaje desde sus orígenes chinos, se atreve a ir concretando criterios - una palabra, unas pinturas, unos jardines, una literatura, una reflexión, una arquitectura o una toponimia- que permitan diferenciar culturas estrictamente "paisajísticas" de otras meramente "paisajeras". Es decir, que en el largo proceso de vinculación cultural significativa de las sociedades humanas con sus respectivos paisajes, parece existir unos "antes" (paisajero y protopaisajístico), que conceden a cualquier sociedad la capacidad de mantener una relación visual, dominadora, identitaria y primariamente afectiva con su entorno, y un "después" (paisajístico), que distingue a ciertas sociedades que han sabido elaborar unas culturas explícitas del paisaje caracterizadas por aquellos anteriores criterios, que aparecen sin duda en dos grandes civilizaciones de la historia de la humanidad: China a partir del siglo IV y Europa a partir del siglo XVI (Berque et al., 1994).

La noción de "cosmofanía" -explicación de su propia realidad por parte de una sociedad humana- es usada por Berque para argumentar por qué el término paisaje ha aparecido en cierta época de la historia y no en otra, en tal o cual mundo y no en otro (Berque, 2006). Las relaciones de las sociedades humanas con su entorno se basan en una aprehensión y predicación de la superficie terrestre ("cosmofanía"), y tal predicado general tiende a concretarse en múltiples predicados particulares de cada cultura y de cada momento, en base a los cuales, el sujeto de cada cultura aprehende y expresa su propia realidad, es decir, su propia cosmofanía, que se va manifestando o desapareciendo según una determinada coyuntura histórica (Berque, 2007, p. 43).

En nuestras latitudes, la mayoría de los tratadistas del paisaje parece compartir -con más o menos matices - la hipótesis berquiana y su corolario de distinguir a la China del siglo IV y la Europa del Renacimiento como culturas plenamente paisajísticas. No obstante, el conflicto se localiza al intentar aplicar tal calificativo a culturas anteriores y/o distintas a éstas. ¿Cuándo se entiende, pues, que una sociedad asume culturalmente la realidad de sus paisajes o los considera como tales? ¿Podría constituir el menhir una primera prueba física de la transformación de la relación hombre-medio en paisaje? ¿La vinculación comunitaria con lo sagrado o la unión mística con la madre tierra no pudieran ser también criterios básicos y sustanciales para considerar paisajísticas a algunas culturas precolombinas? (Rivasplata, 2011). 
Alain Roger plantea también sus dudas ante la hipótesis de Berque: "¿Pero es así de sencillo y debemos negarle toda sensibilidad paisajística a ciertas sociedades por el hecho de que no exista la palabra en su lengua y de que sus representaciones sean concisas, por oposición a las descripciones elaboradas y a las vistas panorámicas a las que estamos tan familiarizados? No estoy tan seguro de ello." (Roger, 2007, p. 57). Y, a partir de su discurso sobre la "artealización" como productora de la metamorfosis de país a paisaje-, se refiere a la posibilidad de que existan culturas que medien entre la ausencia de paisaje y la expresión del mismo como tal, es decir, sociedades que presenten una sensibilidad paisajística aunque no cuenten con un léxico referido al paisaje en los términos en los que se entiende hoy en día, llegando a considerar excesiva y limitante la obsesión berquiana sobre el léxico, ya que dificulta ver más allá, como si la ausencia de una denominación específica implicara la ausencia de emociones y capacidades culturales.

Con tales postulados, hay que reconocer sensibilidades paisajísticas a determinadas culturas, como por ejemplo, al antiguo Egipto, Mesopotamia o Persia - productoras de importantes jardines de recreo y referentes para el posterior desarrollo del arte de la jardinería- o a Grecia y Roma cuyos paisajismos presentan numerosos indicios: elecciones de emplazamientos, representaciones murales (Pompeya), descripciones de paisajes imaginarios, amables, placenteros (Homero, Virgilio, Horacio...) - aunque carezcan de vocablos precisos.

Por su parte, Raffaele Milani ofrece nuevos matices a este debate sobre el origen del paisaje y del paisajismo. Aunque en una primera instancia se alinea con A. Roger, al considerar discriminatorio clasificar a las sociedades en paisajísticas o no paisajísticas en virtud de una serie de criterios, no termina compartiendo todos sus planteamientos al entender que diverge demasiado de la opinión común y aceptable al considerar - con su "artealización" - que el pasaje es "una adquisición cultural o, más detalladamente, una invención histórica debida esencialmente a la obra de los artistas, entre el arte de la jardinería y el Land Art." (Milani, 2007, p. 56). A pesar de reconocer que la concepción de Roger, ligada a la evolución de la pintura, a los descubrimientos científicos y a la experiencia estética del paisaje, es la que se ha ido imponiendo, Milani la critica porque no tiene en cuenta la primaria relación hombre-naturaleza en la complejidad de la existencia humana. Antes de que se constituyese en una representación artística, "el paisaje era una gran experiencia de la emoción, de la visión y de la contemplación, pero así mismo del trabajo humano sobre el territorio y el ambiente... el paisaje es así una aventura de nuestro hacer, de nuestra mirada y de nuestro espíritu, porque sólo establece reglas provisionales y cambiantes; los cánones de la visión, aunque se reiteran en la historia, viven de superaciones permanente" (Milani, 2006, pp. 55-56). Los actos de la visión y de la emoción, más primitivos que las elaboraciones de la pintura y la poesía, son al mismo tiempo antiguos y modernos y constituyen el denominador común paisajístico entre las culturas primitivas y/o antiguas y las modernas. Y son precisamente aquellas culturas más primitivas las que han ido transformando nuestra capacidad de ver y sentir a partir de un 
reconocimiento común: la participación en la vida del mundo. Luego, es el hombre quien a lo largo de su historia ha ido transformando el paisaje en una idea estética a través del arte (Milani, 2007, 2008). Es, pues, necesario distinguir entre el paisaje, que deriva de país, y el paisajismo pictórico o creativo, pues sólo así se puede tomar conciencia del paisaje anterior al sentimiento estético, donde hombre y naturaleza eran partes de una única totalidad. En base a esto, parece que cada época y cada sociedad ha cultivado culturalmente el propio paisaje, existiendo formas diferentes de concebirlo, desde la totalidad del cosmos a la separación total del hombre y la naturaleza en la Edad Moderna, gracias a la evolución del mirar según los dictados del descubrimiento científico y la historia del arte. En función de ello, R. Milani no acepta que la Grecia antigua sea una sociedad protopaisajera, sino más bien todo lo contrario, pues a pesar de no contar con una palabra específica para aludir al paisaje, si poseía varias expresiones y términos que muestran un amor profundo por la naturaleza en relación al "espíritu del lugar" o genius loci ${ }^{1}$ (Milani, 2007).

Otra posición interesante en esta presentación sintética de miradas al origen del paisaje es la que sostiene Francesco Careri, quien, aunque no entre directamente en el debate sobre el origen del paisaje, asume que ya existía y se hacía paisaje por parte de las sociedades prehistóricas. "Hemos escogido el recorrido como una forma de expresión que subraya un lugar trazando físicamente una línea. El hecho de atravesar -como instrumento de conocimiento fenomenológico y de interpretación simbólica del territorio- es una forma de lectura psicogeográfica del territorio comparable al walkabout ${ }^{2}$ de los aborígenes australianos" (Careri, 2002, p. 11). Ante todo, el recorrido nace de la necesidad natural de encontrar los elementos que permitan la supervivencia. Pero, una vez cubierta esta necesidad, el acto de andar se convierte en una acción simbólica que permitió que el hombre habitara el mundo, modificando así los significados del espacio atravesado. El recorrido es, por tanto, la primera acción estética que penetró en los territorios del caos natural para implantar un nuevo orden. Andar se concibe como una forma de arte, una manera obvia de mirar el paisaje natural y empezar a construirlo. Si bien, "la acción de andar no implica una construcción física de un espacio, pero sí una transformación del lugar y de sus significados...sólo la presencia física del hombre en un espacio no cartografiado, así como la variación de las percepciones que recibe del mismo cuando lo atraviesa, constituyen ya formas de transformación

1 “....] Para los griegos, la hyle era una maravilla; el hombre conoce a través de la observación. De hecho, regía por aquel entonces un vínculo entre la vista (thea) y la maravilla (thauma). Los dioses eran el espíritu del lugar, los entopioi theoi recordados por Sócrates en el Fedra, y fuente de inspiración. Se percibe su presencia, se ven y suscitan maravilla. Es el estupor del mirar y del ser mirado. Los hombres pueden ver el dios, pero también los dioses los observan por encima de los montes, de los árboles, entre los arroyos, en la alegría de una participación estética que sobrevive en los siglos y que nace de una concepción animista" (Milani, 2007, p. 150).

2 "El walkabout -palabra intraducible, sólo comprensible en el sentido literario de 'andar sobre' o 'andar alrededor' es el sistema de recorridos a través del cual los pueblos de Australia han cartografiado la totalidad del continente. Cada montaña, cada río y cada pozo pertenecen a un conjunto de historias/recorridos -las vías de los cánticos- que, entrelazándose constantemente, forma una única "historia del tiempo del Sueño", que es la historia de los orígenes de la humanidad. Cada recorrido va ligado a un cántico, y cada cántico va ligado a una o más historias mitológicas ambientadas en el territorio" (Careri, 2002, p. 48). 
del paisaje que, aunque no dejan señales tangibles, modifican culturalmente el significado del espacio y, en consecuencia, el espacio en sí mismo" (Careri, 2002, p. 51). Antes del neolítico esta era la única forma de modificar el entorno desde un punto de vista perceptivo y creativo, lo que permitió pasar del espacio irracional y causal al orden y la geometría, del utilitarismo para la supervivencia a la atribución al espacio físico de unos significados místicos y sagrados. Posteriormente, el menhir se levanta como el primer objeto situado del paisaje humano; establece un nuevo sistema de relaciones entre el hombre y los elementos que forman parte del paisaje.

Esta muestra de distintas posiciones sobre el origen del paisaje, nos permite ya ir subrayando la amplitud y diversidad epistemológicas que envuelven al concepto desde sus propios inicios, en los que ya se atisban diferencias entre unas concepciones más elitistas y otras más universalistas del paisajismo primero. Y tal debate está fuertemente ligado a la propia definición de paisajismo, como actitud primaria del hombre en su relación con el medio o como final de un proceso cultural marcado por momentos graduales entre el no paisajismo, el protopaisajismo y el paisajismo culminante y distintivo. Pero a su vez, el acto de definir el propio paisaje conllevará serios problemas de consenso, como una prueba más del carácter complejo del término.

\section{Romanticismo y posmodernidad consolidan la complejidad del paisaje}

La progresiva consolidación de la complejidad del paisaje como realidad y como concepto pasa en la modernidad occidental por la acumulación de caracteres que le van introduciendo los sucesivos paradigmas del romanticismo y el posmodernismo en sus respectivos contextos. El Romanticismo desde finales del siglo XVIII, cuando la revolución industrial estaba suponiendo la desaparición del antiguo límite entre "el mundo natural", ajeno a los asuntos del hombre, y el "mundo humano"asienta las bases que fundan el paisajismo moderno. $Y$, desde mediados del siglo XX, será en el paradigma posmoderno y en el marco de la globalización, donde el paisaje también se redescubre y globaliza, alcanzando unas dimensiones de aprecio y divulgación que sobrepasan las fronteras del arte y de la geografía, en un proceso similar al romántico, pero con mayores y más extensas consecuencias.

Desde finales del siglo XVIII, el ideario romántico, lleno de sentimiento y sensibilidad, impregna el mundo de las expresiones artísticas e, incluso, el de las ciencias naturales, que experimentan en esta época un gran desarrollo, en un contexto de conexiones entre arte y ciencia, entre explicación y comprensión (Ortega Cantero, 2006). El naturalismo científico experimenta asimismo un profundo cambio en la forma de sentir y valorar la naturaleza, en la forma de entender las relaciones entre los seres humanos y su entorno natural, centrando sus estudios en la explicación del orden natural del mundo en su conjunto. Pero, además, los renovados modos de ver, de pensar y de sentir del romántico aportan nuevas métodos de aproximación científica de índole más artística o poética, que no buscan solo explicar las cosas, sino comprenderlas, así como entender sus cualidades y sus 
valores. De manera que aquellas ciencias naturales quieren conjugar la razón "científica" con el subjetivismo romántico, pues se entiende que el hombre forma parte de ese orden natural y no es ajeno al sistema de correspondencias universales. Esta forma de pensamiento, que se conoce como analogía, ${ }^{3}$ constituye el eje vertebrador de la nueva perspectiva naturalista (Ortega Cantero, 1988).

El paisaje se convierte, durante esta época, en una de las principales temáticas de la vida cultural que propaga así sus valores estéticos, al ser considerado no sólo como un conjunto de formas que hay que explicar, sino también como un conjunto de cualidades, valores y significados que hay que comprender. Estos son los nuevos paradigmas que fundamentan la geografía moderna y, por consiguiente, la concepción moderna del paisaje (Ortega Cantero, 2006), que rebasa en este contexto romántico los límites del arte para abrirse al conocimiento científico, en cuyo seno gracias a la obra de los fundadores de dicha geografía, Alexander von Humboldt y Carl Ritter- se plantan las raíces para el posterior desarrollo de una teoría o ciencia del paisaje. (Ortega Cantero, 1988). "Todo paisaje suponía, en la perspectiva de la geografía moderna, una realidad formal y una imagen cultural. [...] La visión del paisaje vertebrada por la geografía moderna aúna la perspectiva científica, explicativa, y la perspectiva cultural, comprensiva, que se adentra en el mundo de las cualidades, de los valores y de los significados." (Ortega Cantero, 2006, pp. 108109).

Aquella primera reconceptualización en torno al paisaje se extendió a lo largo de todo el siglo XIX y parte del XX, periodo durante el cual las diferentes corrientes de pensamiento geográfico fueron incorporándose al estudio del paisaje y marcando sus bases teóricas. De este modo se llega a la década de los años 30 del siglo XX, cuando el geógrafo alemán Siegfried Passarge publica un primer tratado científico sobre una disciplina emergente: la Geografía del Paisaje, es considerada el acta de nacimiento de la Ciencia del Paisaje, de gran implantación a lo largo del siglo pasado y que ha llegado a nuestros días (Arias, 2003).

Por otra parte, desde la segunda mitad del siglo XX y en el marco de la globalización y el paradigma de la posmodernidad, tiene lugar un segundo redescubrimiento moderno del paisaje que añade nuevos caracteres a su conceptualización y cuyas consecuencias, como antes se ha señalado, serán mayores y más extensas, aunque no necesariamente más importantes que las producidas durante el Romanticismo.

3 "[...] Procede ésta de una tradición muy antigua -recogida por el neoplatonismo renacentista y transmitida por corrientes herméticas o heterodoxas que la aproximan hasta la modernidad decimonónica- y sostiene «la visión del mundo como un sistema de correspondencias». Es una visión que se opone a las pretensiones analíticas y disociadoras del racionalismo. [...] La analogía es el reino de la palabra, como ese puente verbal que, sin suprimirlas, reconcilia las diferencias y las oposiciones. [...] la analogía es la operación por medio de la que, gracias al juego de las semejanzas, aceptamos las diferencias" (Ortega Cantero, 1988, pp. 31-32). 
Una de tales consecuencias será el enriquecimiento de la recién creada Ciencia del Paisaje, que desborda las fronteras de la geografía y empieza a llamar la atención de otras disciplinas, con las que establece un flujo de información bidireccional:

La Ecología, que en estos momentos experimenta un gran auge debido al interés social creciente por la conservación del medioambiente ante la acción agresiva y depredadora del hombre, aportará a la Ciencia del Paisaje nuevos puntos de vista en la forma de concebir los niveles de organización de la superficie terrestre basados en la teoría general de sistemas, de cuya aplicación a los estudios de paisaje surgirá el concepto de geosistema, ${ }^{4}$ que se desarrollará dentro de lo que ya se conocía como Ecología del Paisaje, introducida por Carl Troll en 1938 (Bolós, 1992). Los ecólogos españoles Ramón Margalef y Fernando González Bernaldez se convertirán en pioneros en el entendimiento del contenido paisajístico como expresión de las múltiples y recíprocas relaciones existentes en un fragmento de la superficie de la Tierra, en el que quedan incluidos no sólo los elementos naturales, sino también las estructuras socioeconómicas y las percepciones (Margalef, 1974; González Bernáldez, 1981).

La percepción o el análisis del paisaje visual se incorpora también a los estudios paisajísticos de la mano de los analistas económicos regionales, entre los que destacan el geógrafo y economista Walter Isard, y de los urbanistas de la escuela de Chicago, cuya máxima figura, Kevin Lynch, fue pionero en la realización de mapas cognitivos urbanos. (De la Fuente-de Val, 2004).

$Y$, desde otras disciplinas, interesadas por el paisaje, fueron surgiendo nuevas ramas de estudio que giraban en torno a él: la Arquitectura del Paisaje, el Paisajismo, la Ingeniería del Paisaje, la Arqueología del Paisaje o la Psicología Ambiental.

Asimismo, se produce una eclosión de la plástica y la creatividad en el paisaje y se desarrollan las formas de mirarlo que introducen las nuevas tecnologías:

El movimiento artístico del land art toma el relevo de la pintura de paisaje para iniciar una nueva forma de aproximación al mismo. Se busca reflexionar, principalmente, sobre la complejidad de las relaciones entre la civilización y la naturaleza, la incertidumbre de los efectos de la tecnología y la industria en el medio natural. Los artistas del land art no están interesados en la representación de la naturaleza a través del paisaje, sino en la experiencia de la misma, lo que conlleva un cambio del papel del espectador frente a las obras (Llorens, 2006, p. 121). Dentro del land art aparecen dos

4 "El geosistema corresponde a un determinado tipo de sistema. El concepto fue definido por el geógrafo soviético Sochava, en 1963, y fue utilizado en inglés en 1967 por el geógrafo Stoddart y en alemán en 1969 por Neef. A partir de estas fechas se trata ya de un término científico utilizado por todos los especialistas de la Ciencia del Paisaje. Corresponde a la aplicación del concepto de sistema y a la concepción sistémica del paisaje. El geosistema, como el ecosistema, es una abstracción, un concepto, un modelo teórico del paisaje. En él encontramos todas y cada una de las características que hemos definido como propias de todo sistema" (Bolós, 1992, p. 36). 
corrientes: la americana -cuyos artistas serán los pioneros del movimiento y se caracterizará por el monumentalismo y gigantismo de sus obras, el desinterés hacia el lugar o la imagen de predominio de la técnica sobre el entorno natural- y la europea - que intentó alejarse de aquellas formas de proceder y acercarse más a las huellas de la memoria en los lugares o a aquello que les confiere una singularidad o carácter propio, incluso concibiendo el paisaje desde una óptica que vinculase la plástica con la poesía o la literatura- (Llorens, 2006).

La fotografía, la publicidad o el cine se nutren del paisaje y de la gran riqueza simbólica que encierra. El paisaje es utilizado para transmitir o comunicar determinados mensajes sin necesidad de utilizar palabras, ampliando y democratizando significativamente el imaginario espacial de las comunidades locales (Gámir, 2012).

Aquellas nuevas tecnologías condujeron también a valorar las percepciones del paisaje por otros canales diferentes a la vista, hasta ahora predominante tanto en los estudios científicos como artísticos. El paisaje sonoro comienza a tener importancia a partir de finales de los 60, momento en que se pone en marcha el World Soundscape Project en la Universidad Simon Fraser de Canadá, que documenta los ambientes acústicos, tanto funcionales como disfuncionales, para generar una conciencia pública sobre la importancia del paisaje sonoro apelando directamente a la sensibilidad auditiva del individuo (Truax, 2001). El paisaje sonoro (soundscape) es entendido como el entorno sonoro concreto de un lugar real dado y no sólo es concebido en términos de contaminación acústica, sin que también puede ser una composición musical de sonidos ambientales que debe buscar la reintegración del oyente en el ambiente en una relación ecológica equilibrada (Truax, 1994).

Y quizás las más recientes aportaciones a la complejidad del paisaje estén viniendo de la mano de sus consideraciones como recurso y como patrimonio:

En el paradójico contexto actual - de intensificación de los procesos de degradación paisajística producida por la ruptura del equilibrio hombre-naturaleza y el acelerado desarrollo tecnológico y, a su vez, de aprecio social creciente de los paisajes que se perciben como algo más que una serie de valores formales- empieza a entenderse el paisaje como un factor de calidad de vida y bienestar y como un recurso de gran valor, todo ello imbricado en el avance general de la concienciación ambiental (Zoido, 2000; Mata, 2006). Se puede decir, en el sentido socioeconómico del término, que el paisaje es un recurso porque cumple las dos condiciones necesarias del mismo: utilidad para la población y escasez para que resulte realmente un bien económico. Desde el punto de vista perceptivo el paisaje es ilimitado y no tendría esta consideración, pero en términos cualitativos la degradación de los valores paisajísticos hace que mermen los paisajes de calidad y, por tanto, que escaseen (Gómez Orea, 1994). Y esta escasez ha sido bien aprovechada por la industria turística, publicitaria y televisiva, que ha sometido al 
paisaje a "un proceso generalizado de "estetización", a una especie de "domesticación" de consecuencias problemáticas" (Llorens, 2006, p. 118), por lo que conllevan de tipificación y banalización de imágenes paisajísticas.

Ligada a tal entendimiento del paisaje como recurso surge la concepción patrimonial del mismo (Silva \& Fernández, 2017). El paisaje actúa como memoria colectiva, como punto de referencia de la identidad. El observador ve en el paisaje un documento territorial transmitido entre generaciones que debe ser leído e interpretado, que contiene todo el proceder histórico y cultural de la acción del hombre sobre la naturaleza (Mata, 2006). Existe, pues, una voluntad social cuya intención es la de recuperar la proximidad al lugar y a su historia, de restablecer los lazos de unión entre el hombre y su entorno más inmediato a través de nuevos canales donde el paisaje recupere su verdadero valor, y de apreciar y aceptar la diversidad natural y cultural por parte del individuo y de las comunidades que viven en medios descontextualizados y aterritoriales. Éstas son las claves del renovado interés por el paisaje en medio de una situación que tiende a homogeneizar contextos para ir perdiendo progresivamente identidades y realidades cotidianas. (Español, 2002).

Y algunos corolarios de estas consideraciones del paisaje como recurso y patrimonio, son, entre otros, el surgimiento del concepto de paisaje cultural ${ }^{5}$ y la necesidad de establecer políticas del paisaje y de reconocer el derecho al paisaje, es decir, de desarrollar medidas y estrategias, tanto políticas como normativas, que permitan la ordenación, gestión y protección de los paisajes (Zoido, 2002).

Como colofón de este apartado, puede decirse que hoy el paisaje está presente en gran parte de las dimensiones que configuran la vida humana: las ciencias, las humanidades, el arte, la economía, el derecho, las políticas públicas, las demandas sociales, la calidad de vida... Todo ello ha conllevado a pensar, sentir, imaginar, analizar, explicar, comprender, interpretar, inventar, intervenir, proyectar, planificar, legislar... el paisaje desde diferentes perspectivas, contribuyendo a forjar y consolidar su complejidad como la principal de sus cualidades.

\section{La compleja dialéctica del paisaje, sus tensiones y síntesis}

Sobre el paisaje recaen a menudo fuerzas antagónicas; incertidumbres y multiplicidades que emanan de su propia concepción compleja, pero que a su vez retroalimentan su más que difícil determinación. En definitiva, se puede decir que el paisaje es tensión (Wylie, 2007; Cano, 2011), presentando un carácter dialéctico entre dos fuerzas en primera instancia contrapuestas: "realidad-

5 "El paisaje cultural es el resultado de la interacción en el tiempo de las personas y el medio natural, cuya expresión es un territorio percibido y valorado por sus cualidades culturales, producto de un proceso y soporte de la identidad de una comunidad. En este sentido, el paisaje cultural es una realidad dinámica, resultado de los procesos que se producen a lo largo del tiempo en un territorio, y compleja porque la integran componentes naturales y culturales, materiales e inmateriales, tangibles e intangibles." (MECD, 2017). 
imaginario", "natural-humano", "percepción-proceso", "espacio-tiempo", "extraordinario-cotidiano" o "visible-invisible". El paisaje es una realidad natural pero también es un imaginario producto de la cultura humana. El paisaje es resultado de la inmediata percepción humana, de la forma en que aprehendemos el mundo que nos rodea, pero también es resultado de un conjunto de procesos generadores de diversas formas de organización. No obstante, tanto la percepción humana como las dinámicas de organización dependen del espacio, que contiene la materia existente sobre la cual se ejerce la percepción y tienen lugar los procesos, y del tiempo, tanto histórico como reciente, que es el que infunde el carácter mutable a la percepción, a los procesos y al espacio (Mata, 2006). El tiempo es lo que hace que el paisaje sea un medio dinámico, pero no todos los paisajes se ven influenciados de igual forma por el tiempo, todo depende de la velocidad a la que se suceden sus transformaciones (Galí, 2007).

Por otra parte, la dualidad "extraordinario-cotidiana" ha implicado hasta ahora una oposición casi insalvable: el hombre siempre ha interpretado como extraordinario lo que queda fuera de su entorno cotidiano. Hasta la modernidad, lo extraordinario se identificaba con la naturaleza salvaje y era sinónimo de "horrible". El Romanticismo, a través de la sensibilidad paisajística, conlleva un descubrimiento de lo extraordinario como algo bello; la montaña, el mar o los glaciares dejan de ser vistos como un "país horrible" para ser interpretados como un "paisaje sublime" (Roger, 2007). En la actualidad, la "colonización" humana del espacio natural ha dado paso a una concepción cotidiana del mundo, en la que apenas existe lo extraordinario en el sentido romántico; el hombre encuentra lo extraordinario en los paisajes "arquetípicos" o estereotipados por el poder de la imagen (Nogué, 2007, p. 379). Sin embargo, es posible ir más allá y poner ambas expresiones en relación: buscar lo que de extraordinario tiene lo cotidiano. $Y$ es que, en el actual contexto globalizado, la búsqueda de lo extraordinario dentro de lo cotidiano supone reconocer los símbolos y particularidades que aportan identidad y significado a cada paisaje.

Asimismo, puede distinguirse otra dualidad aplicada a la consideración del paisaje como "visibleinvisible". El paisaje visible se corresponde con los elementos estructurales, las formas, los colores, las texturas, las escalas, en definitiva, con la imagen final tangible que percibimos y su estética. E paisaje invisible es más complejo, pues en él se conjugan las dinámicas y las interrelaciones entre elementos, las emociones y los sentimientos del ser humano y la dimensión intangible de la percepción, como es el caso de los olores y los sonidos. Finalmente, y de forma más abstracta, las ausencias y los vacíos dejados por la historia, lo que ya ha desaparecido y queda en la memoria, también se incluye dentro del paisaje invisible. De hecho, lo visible en cada momento se sustenta en las dimensiones de lo invisible.

Ligado a estas dicotomías surgen otras nuevas que vienen a confirmar una vez más la complejidad que encierra en sí mismo el paisaje. John Wylie propone otras tensiones del paisaje - "proximidadlejanía", "habitar-observar" o "territorio-manera de mirar"- que se resumen de la siguiente forma: 
"¿̇es el paisaje el mundo en el que vivimos, o es la escena que miramos, desde la distancia?" (Wylie, 2007, p. 1). De esta forma se plantea muy acertadamente cómo nos aproximamos al paisaje en términos de lejanía, condición que subordina la percepción del mundo más inmediato al sujeto (Wylie, 2007; Cano, 2011, p. 30).

Pero las dos tensiones que podrían ser consideradas más características del paisaje son "objetosujeto" y "estética-ética". El "objeto" es todo aquello que sustenta físicamente el paisaje (los componentes estructurales y funcionales, las morfologías y las dinámicas) y que constituye materia de conocimiento y sensibilidad por parte del "sujeto". Por el contrario, éste hace alusión al espíritu humano, a la forma en que se percibe y aprehende el "objeto", por lo que el "sujeto" es considerado en oposición al mundo exterior, al cual está expuesto. Es decir, el paisaje es una dimensión física, material y objetiva, pero también es una dimensión espiritual, cultural y subjetiva (Nogué, 2008). Y toda modificación sufrida por el "objeto" afecta al "sujeto" y viceversa. Por tanto, existe una conexión real entre ambos que va más allá del entendimiento de cada uno por separado.

Sin embargo, no siempre es entendida y aceptada esta relación complementaria y necesaria, reduciendo al "objeto" y al "sujeto" a dos proposiciones extranjeras o contradictorias: "el paisaje es una naturaleza-objeto", un fenómeno natural, una realidad independiente de la observación y del observador, y "el paisaje es una naturaleza-sujeto", un fenómeno cultural sustentado en diferentes mecanismos psicológicos, lingüísticos, económicos o ideológicos (Bertrand, 1978). De esta forma surge, por un lado, el llamado "enfoque objetivista" que trata, clasifica y valora el paisaje en base a métricas establecidas según características físicas y ecológicas independientes del "sujeto", el observador, y del proceso de percepción. Al otro lado, encontramos el "enfoque subjetivista", que desatiende la existencia material del paisaje para centrarse en las percepciones de las poblaciones y así construir el conocimiento científico del paisaje.

El paisaje es más que esto, es a la vez "objeto" y "sujeto", es realidad física e imaginario cultural, ya que como concepto originalmente taoista es un ying-yang que sólo puede ser entendido como interacción compleja de estas dos proposiciones (Berque et al., 1994; Besse, 2006). A partir de aquí emerge otra dualidad clave, "estética" y "ética", que ya una vieja máxima confuciana ponía en relación directa y complementaria con el paisaje: "El hombre bueno (ética) se alegra (estética) con el paisaje".

La "estética" hace referencia a la percepción o apreciación de la belleza, por tanto, una "estética del paisaje" sería definida como la percepción o apreciación de la belleza de la naturaleza (Venturi Ferraiolo, 2007). Pero la naturaleza no es ni bella ni fea, sino que la belleza es una forma específica de percibir la naturaleza, es ya de por sí una imagen que se conjuga con una reacción sentimental del hombre en el ámbito de la abstracción mental (Zimmer, 2008; Milani, 2008). La 
belleza o, más bien, la experiencia estética del paisaje, no emana de la naturaleza en sí misma sino del hombre, de su psicología y de la construcción cultural. El hombre siempre ha experimentado una atracción por la naturaleza que le rodea y que estéticamente se ha mostrado ante él a través del paisaje. Y la construcción estética del paisaje depende de cómo se conjuga un determinado conjunto de formas para dar lugar a un determinado orden, que se presenta ante nosotros. La experiencia estética del paisaje es una acción individual y, en principio, interior, pero que se externaliza cuando utilizamos las técnicas artísticas para dejar constancia de esa experiencia. A partir de estas constancias artísticas, se van construyendo los cánones y arquetipos de la estética del paisaje, muy vinculados a cada sociedad y a cada momento histórico.

Aunque el hombre desde siempre ha transformado la naturaleza y la ha cargado de significados y símbolos, construyendo así el paisaje y transformándolo en una idea estética, es ahora cuando se enfrenta a la desaparición de sus valores estéticos por la acción humana. El poder técnico destruye y transforma los paisajes a mayor velocidad que su posibilidad de regeneración o asentamiento y de producción de nuevos valores estéticos consensuados socialmente. Tal paradoja es la que genera una interpretación del paisaje como recurso y patrimonio y la necesidad de establecer para su protección una "ética" de la estética del paisaje.

La "ética" comporta el conjunto de normas morales que rigen la conducta humana, el sistema de creencias aceptadas que dictan nuestro comportamiento como sociedad, en definitiva, el denominador común central con el que todos podemos identificarnos (Andersson, 2007, p. 73). Una "ética del paisaje" debe tratar la relación entre hombre y naturaleza, entre el "sujeto" y el "objeto", y no la relación entre individuos. Y esta relación es, por ende, asimétrica puesto que cedemos derechos a la naturaleza que ésta no puede reclamar $y$, por el contrario, la naturaleza no tiene deberes para con el individuo. Esto supone un importante problema para la internalización de una ética del paisaje, puesto que la teoría ética clásica se basa en el reconocimiento recíproco, en la relación de simetría: "mi reconocimiento del otro tiene su fundamento en el ser reconocido por el otro" (Zimmer, 2008, p. 34). Pero en contraposición a la visión tradicional y clásica de la "ética", surge una nueva teoría de la "ética de la responsabilidad", que se sustenta en el reconocimiento no recíproco y unilateral del otro. En base a esto, se exige reconocer los derechos, no sólo de la naturaleza, sino también de las generaciones futuras, de los cuales no se puede derivar ningún deber hacia nosotros. Esta nueva visión de la "ética" es considerada más acorde con la época actual, donde el poder de la técnica sí es moralmente relevante, pero conlleva un problema importante: ¿cómo hacer obligatoria una relación ética no recíproca? La respuesta está en la autoobligación voluntaria, puesto que la relación del hombre con la naturaleza es mayoritariamente de utilidad y es lo que determina la transformación de los paisajes (Zimmer, 2008).

Por tanto, la ética de la responsabilidad permite entonces establecer un "derecho del paisaje", en tanto en cuanto el paisaje es considerado "sujeto de derecho". Ahora bien, el paisaje no puede 
defenderse ni reivindicar sus derechos, es decir, que necesita de un "representante" humano sobre el que delegar y que éste se encargue de tales asuntos (Roger, 2007). ¿Pero hasta qué punto este "representante" del paisaje puede garantizar la defensa de los verdaderos derechos y deberes del paisaje? ¿Cómo podríamos estar seguros de que éstos provienen realmente del paisaje en sí mismo, como sujeto, y no están influenciados por los deseos y principios morales de su "representante"? Asimismo, desde el punto de vista del ordenamiento jurídico, "el derecho tiene como misión legislar, sobre la base de un proceso democrático, sobre lo que es bueno y lo que es malo para la sociedad humana. Pero eso no quiere decir que el derecho deba establecer lo que es bello y lo que no lo es" (Priore, 2002, p. 94). El derecho no puede proteger tal o cual valor concreto, pero sí la concepción "social" del paisaje que representa la voluntad de las poblaciones. En este sentido, hablamos del derecho de los ciudadanos a establecer una relación sensible con el territorio y beneficiarse de ella, a participar en las decisiones con respecto a las características formales de sus entornos más inmediatos, a un paisaje de calidad y a preservar los valores espirituales y sentimentales que lo vinculan con sus espacios cotidianos. Es decir, hablamos del paisaje como un "interés común" de la sociedad que le compromete y obliga a establecer contratos entre individuos (Roger, 2007). Por tanto, es posible entender el paisaje como "objeto de derecho" y sí existiría la posibilidad de establecer un "derecho al paisaje" (Priore, 2002). Sobre las bases de este paradigma no es posible fundamentar una ética del paisaje, pero si una ética de la estética del paisaje.

Una última cuestión sería: ¿es ésta una visión "integradora" o más bien "desintegradora"? El carácter tensionado del paisaje es el reflejo de la compleja posición que este concepto ocupa en el saber humano. Cada dicotomía está formada por expresiones normalmente asumidas como opuestas, pero ambas forman parte del paisaje porque, cada una a su modo, le dan sentido. Joan Tort (2006) considera que el paisaje debe situarse en lo que se ha convenido en llamar "transversalidad epistemológica", de manera que entre las dos expresiones que componen cada una de las dualidades no debe o no puede existir una oposición en sentido estricto, ya que entre ambas partes se establecen interrelaciones y complementariades que enriquecen en gran medida al paisaje. Debemos ver que éstas no son visiones parciales de una misma realidad, sino que participan de la multidimensionalidad de este gran holos que es el paisaje.

\section{El diálogo de discursos en la redefinición del paisaje}

El paisaje es de esos conceptos que todo el mundo intuye o sabe más o menos en su fuero interno lo que es. Esa intuición se equipara casi a entender el paisaje como panorámica sobre el campo, lo que la persona, concretamente, tiene ante sus ojos, y con lo que se establece una relación más o menos explícita de juicio valorativo que tiene como resultado una serie de interpretaciones en relación a la identidad, la pertenencia o la emoción (Bonin, 2002). Tal concepción responde a que 
la población tiene interiorizada esas primeras definiciones del paisaje, que no han cambiado demasiado desde el siglo XVIII, y que hacen siempre alusión a la porción de terreno que el ojo puede abarcar de un simple vistazo, incluyendo, especialmente, su aspecto pictórico. Pero a la hora de concretarlo resulta difícil: "Me pregunto por qué tenemos problemas en ponernos de acuerdo sobre el significado de landscape [paisaje]. La palabra es lo suficientemente sencilla y alude a algo que creemos que entendemos, y, sin embargo, parece que significa algo diferente para cada uno de nosotros" (Brinckerhoff, 2010, p. 29). Normalmente es confundido con otras expresiones tales como "entorno", "naturaleza", "ambiente", "lugar" o "territorio". El equívoco más frecuente es entre "paisaje" y "naturaleza", porque la población común ha interiorizado que la ciudad o el espacio urbanizado quedando fuera del paisaje: sólo los fenómenos y elementos naturales son paisaje. El paisaje no es ninguna de ellas. Es otra cosa. Es algo que se balancea entre los límites conceptuales de aquellos términos. Ejemplo de ello es la presencia de muchos puntos en común entre los concepto de "paisaje" y de "territorio" -ambos son una porción de terreno visto/ocupado por una persona-, que sólo a cierto nivel de detalle ofrece matices particulares y específicos (Tort, 2006).

A partir de la asunción del paisaje como objeto de estudio científico, la palabra sufre un préstamo lingüístico por parte de diversas disciplinas, lo que se materializa en su dotación de sentidos más concretos y precisos para que el vocablo pueda ser utilizado internamente. El resultado es un concepto de paisaje más polisémico, amplio y diverso, que en muchas ocasiones presenta acepciones contrapuestas. $Y$ ello, unido a posiciones corporativistas ante la creciente demanda profesional que el paisaje está generando, impide que hoy en día se tenga una teoría y un concepto de paisaje ampliamente compartido entre disciplinas y saberes (Mata, 2006). Pero, ¿realmente es necesaria una definición analítica, rigurosa y consensuada? Por oposición, hay quien entiende que el paisaje es una palabra viva, cambiante y cotidiana que cada uno usa a su manera, siendo necesario dejarse guiar por el uso social que se hace de la misma (Bertrand, 1978).

En opinión de Jean-Marc Besse (2006, pp. 145-171) existen en la actualidad "cinco problemáticas paisajeras que coexisten en el pensamiento contemporáneo". En este sentido, el paisaje es definido como:

a) Una representación cultural (principalmente informada por la pintura).

El paisaje es un constructo humano y más allá de ello no existe, ni siquiera, como objeto material. Es el resultado de lo que el hombre piensa de él en función de lo que percibe y de la cultura que le avale. Aquí no cabe la dialéctica entre el objeto y el sujeto o lo real y lo imaginado. El paisaje es siempre interpretado desde la misma óptica, es siempre una expresión humana. Por tanto, el paisaje es una invención artística, pero también es una representación cultural, tanto colectiva como individual. 
Aquí encajan bien las definiciones que elaboran Alain Corbin (2001, p. 32), diciendo que "el paisaje es una manera de leer el espacio, de imaginarlo, de cargarlo de significados y de emociones. Es una lectura indisociable de la persona que lo contempla", y Alain Roger (2007, p. 14), para quien el paisaje es una invención artística y solamente "el arte constituye el verdadero mediador, el "meta" de la metamorfosis, el "meta" de la metafísica paisajística".

Por otra parte, Yves Luginbühl (2012) califica de reduccionista a esta concepción del paisaje, al entenderlo como objeto de arte que el observador contempla, estableciendo con él una relación exclusivamente estética.

b) Un territorio producido por las sociedades a lo largo de su historia, es decir, un territorio habitado y fabricado.

El paisaje es un territorio construido culturalmente. Aunque se parezca a la posición anterior, ésta es distinta, porque allí el paisaje era solamente una representación mental, ya fuera estética o cultural, aquí lo estético no es lo esencial y lo cultural es entendido a nivel material y espacial, es decir, que esta otra perspectiva insiste en la dimensión objetiva del paisaje, reconoce que el paisaje sí existe como realidad material. Sin embargo, el paisaje no debe ser confundido con la naturaleza, no es naturaleza, es la forma como el ser humano se inscribe en ella y la transforma. Por tanto, el paisaje es el territorio producido, fabricado y practicado por las sociedades, que superponen sobre él sus experiencias, prácticas y hábitos a lo largo del tiempo. De manera que, todo paisaje es cultural y no queda separado de la vida cotidiana del hombre; éste se sumerge en el paisaje y toma de él su propia identidad. Nacen aquí las ideas de paisaje "utilitario", paisaje "identitario" y tambien de paisaje "patrimonial" (Silva \& Fernández, 2017).

John Brickerhoff Jackson (2010, p. 38) lo define así: "un paisaje no es un elemento natural del entorno sino un espacio "sintético", un sistema hecho por el hombre, de espacios superpuesto sobre la faz del terreno, que no funciona ni evoluciona de acuerdo con las leyes naturales, sino que sirve a una comunidad [...] un paisaje es un espacio deliberadamente creado para acelerar o retrasar el proceso de la naturaleza [...] representa al hombre que asume la responsabilidad de la función del tiempo".

c) Un complejo sistémico que articula los elementos naturales y culturales en una totalidad objetiva; el entorno material y vivo de las sociedades humanas.

El paisaje es un objeto vivo y real que existe y puede desarrollarse independientemente del hombre. El paisaje no es sólo dominio del ser humano, está constituido también por los diferentes elementos que componen el entorno natural en el cual se desenvuelve la vida humana y que están sometidos a las leyes que le son propias. En oposición a "todo paisaje es cultural", surge ahora la idea de que existen paisajes "naturales". Pero esta oposición no llega a ser tan radical. Se reconoce el hecho de que el paisaje, además de un elemento natural, es un producto social, es 
decir, que en el paisaje se articulan tanto elementos naturales como humanos y la combinación de ellos genera una realidad sintética y/o totalidad específica que es lo que llamamos "paisaje". Esto no quiere decir, ni mucho menos, que se abandone la concepción del paisaje como una realidad independiente de las representaciones y las prácticas humanas. Como tal, es posible estudiar sus componentes y los tipos de relaciones que se establecen entre ellos, así como las dinámicas que dan lugar al aspecto del paisaje.

En esta perspectiva se enmarca la ecología del paisaje. Carl Troll (1950) define el paisaje geográfico como "un sector de la superficie terrestre definido por una configuración espacial determinada, resultante de su aspecto exterior, del conjunto de sus elementos y de sus relaciones externas e internas, que queda enmarcado por los límites naturales de otros paisajes de distinto carácter".

d) Un espacio de experiencias sensibles o fenomenológicas rebeldes a las diversas formas posibles de objetivación.

El paisaje es el acontecimiento del encuentro concreto entre el hombre y el mundo que lo rodea a través de la sensibilidad. El paisaje se presenta como una experiencia que refleja la forma de estar en el mundo del ser humano y cómo éste se ve afectado por ese mundo que le rodea y participa de él; es la prueba de la existencia de un "fuera" -el mundo- y un "otro" -el sujeto-. Y es que, en dicha experiencia, el sujeto es conducido y empujado más allá de sus límites por un "fuera", pero este "fuera" no es un objeto en el sentido de una realidad material y viva. Se está entre los campos de lo sensible y de lo invisible. El paisaje es un realidad sentida (Ortega Cantero, 2007). Por tanto, el paisaje sufre una desobjetivación, no es un objeto que se aprehende, pero tampoco se reduce solamente al sujeto.

El antropólogo japonés Tetsuro Watsuji, en cuya reflexión sobre el paisaje convergen las viejas tradiciones orientales y la moderna fenomenología alemana, se esfuerza en su texto sobre Antropología del Paisaje, para hacerse entender en este complejo asunto, planteando -en síntesislo siguiente: "La importancia del tema del paisaje radica en que nos proporciona orientación definitiva para analizar la estructura de la vida humana. La estructura ontológica de la existencia humana ya no puede captarse a partir de un modo de trascender vinculado exclusivamente a la temporalidad. [...] La trascendencia se realiza (también) por medio de lo concreto del clima y el paisaje en los que el ser humano se descubre a sí mismo. [...] Vistos así, clima y paisaje son el momento de objetivación de la subjetividad humana. La fenomenología del clima (y del paisaje) nos muestra cómo nos descubrimos a nosotros mismos como "ex-sistentes"" (Watsuji, 2006, pp. 3540). 
e) Un sitio o un contexto de proyecto.

El paisaje es la resultante de construir mediante un proyecto una experiencia, es decir, que la experiencia de la realidad paisajística está orientada y concertada de antemano. Estamos dentro del campo de acción del arquitecto y del paisajista, que no intervienen sin una lógica en el paisaje. Como expertos, su labores profesionales se desarrollan en tres direcciones no excluyentes: el "suelo", entendido no solo como material sino también como construcción histórica y al cual se confronta la acción de proyectar; el "territorio", que implica una ampliación de la escala de intervención con respecto al espacio urbano, así como una articulación entre las diferentes escalas existentes, ya sean espaciales, temporales o funcionales; y el "entorno natural", que ya no queda relegado a las afueras de las ciudades, sino que se encuentra dentro de ellas.

En este sentido, Enric Batlle (2011, p. 181) dice que "el jardín de la metrópoli es una estrategia desde el paisaje, el resultado de aprender a fabricar paisajes; una aproximación que incide en el conocimiento del territorio a todas las escalas de trabajo, desde la escala geográfica a la escala individual. La matriz ecológica metropolitana, el sistema de espacios libres urbanos y los entornos de valor añadido tienen sentido como el conjunto de nuevos paisajes que definen la nueva geografía de la ciudad, pero también tiene sentido porque pueden convertirse en una referencia obligada para cada actuación desde la escala local."

Por tanto, el paisaje como proyecto pasa por pensar la ciudad en función de las relaciones que tiene establecidas y de su integración con su suelo, su territorio y su entorno natural. Pasa, en definitiva, por una lectura de sus "paisajes fundantes", sus "escenarios simbólicos" y sus "espacios públicos" desde una óptica de la ciudad inteligente (García, Ojeda-Rivera \& Torres, 2008, pp. 158-162; López Gómez, 2016).

Proyectar el paisaje es, a la vez, ponerlo en imágenes o representarlo -es decir, atestiguar y describir - e imaginar lo que podría ser o llegar a ser -es decir, modificar e inventar-.

Estas cinco formas de clasificar u ordenar los diferentes paradigmas que orientan la concepción epistemológica del paisaje no son estancos cerrados, tal y como reconoce Besse. En un mismo autor podemos encontrar una movilidad flexible entre uno y otro enfoque e, incluso, una superposición de los mismos. Cabe preguntarse cómo esto es posible si algunas de las perspectivas son contrarias entre sí. La respuesta está en abrir todas las puertas y dejar fluir los diferentes discursos para permitir una verdadera experiencia paisajera sustentada en el pensamiento abierto (Besse, 2006). Y es que un sustrato paisajístico suficientemente heterogéneo permite acoger aportaciones originales (Lassus, 2007, p. 90). En este sentido, parece más o menos consensuada la triada "cultura", "historia" y "naturaleza" como base de cualquier reflexión sobre el paisaje, así como un cierto esfuerzo por superar sus dualismos (Llorens, 2006), reconociendo sus tensiones. 


\section{Reflexión final}

Intentar establecer una conclusión inequívoca consensuada sobre el paisaje -realidad compleja, de origen taoista, medial, trayectiva y dialéctica- y sobre el paisajismo -conjunto de discursos confluyentes o divergentes, superpuestos o dialogados- puede resultar un empeño vano y poco operativo. La ecléctica propuesta de J. M. Besse nos ha servido de socorrida tabla de salvación para terminar presentando las complejidades mostradas en cada apartado de este texto como un caleidoscopio de proposiciones o puertas abiertas y todas ellas válidas.

En relación con su origen, entendemos que el paisaje podría concebirse como una actitud hacia el medio, confiriendo una gran importancia al sujeto, pero también al objeto-medio que provoca la actitud. Este concepto primario de actitud nos conduce a evocar, entre los orígenes del paisaje, a las sociedades no paisajísticas y/o protopaisajísticas. En virtud de ello, tendemos a decantarnos con la proposición de que siempre ha habido paisaje, a pesar de que no se cumplan ninguno de los requisitos de Augustin Berque, porque quizás sea más plausible pensar en la posibilidad de que existieran otras formas de entender el paisaje diferentes a las que se han ido elaborando en la modernidad y tenemos interiorizadas actualmente. El hombre primitivo seguramente estableció una relación especial con el entorno que le rodeaba, interpretando y cargándolo de significados dentro de los límites de su comprensión. El problema de este proceso es que, en principio, es individual y no deja huella, es una cuestión interna del sujeto. Sólo cuando el hombre descubre la arquitectura o la pintura empieza a dejar señales de ese entendimiento del mundo.

Pero nuestro principal afán actual -como investigadores y profesores- es aprender y enseñar rigurosamente a leer paisajes. Para ello partimos de la convicción de que -como un vino, como un café o como una sinfonía- el paisaje debe ser catado, percibido y valorado en toda su plenitud. Como los buenos catadores y melómanos cuentan necesariamente con los datos básicos de sus vinos y sus sinfonías a disfrutar y valorar, el lector de paisajes tiene que aproximarse a ellos partiendo ineludiblemente del conocimiento de los distintos análisis disciplinares sobre los escenarios naturales y territoriales en los que se insertan. Pero, el método analítico está pensado para abordar lo complicado, que puede disociarse en partes para entenderlo; mientras que lo complejo - como el vino, el café, la sinfonía o el paisaje- es un tejido que si se disocia se pierde y, por lo tanto -aunque presuponga lo analítico- exige además unos métodos gramaticales que ofrezcan la posibilidad de acceder a la lectura de su conjunto como algo más completo que el mero sumatorio de sus partes. La retórica, la dialéctica, la fenomenología y la hermenéutica nos están ofreciendo buenas pistas de búsqueda de tales métodos y el diálogo inter y transdisciplinar promocionado desde una geografía abierta hacia la convergencia de miradas- nos está sorprendiendo por sus resultados sinérgicos y compartidos. Nuestro maestro Humboldt decía que sólo la convergencia de ciencia y poesía permitiría descubrir los secretos del Cosmos y él - 
científico, poeta, pintor...- descubrió y desveló algunos de aquellos secretos. Nosotros -menos científicos y más prosaicos - sólo podremos leer, comprender y desvelar la complejidad de los paisajes cuando seamos capaces de superar pruritos disciplinares y aprendamos a converger trasdisciplinariamente en la tarea (Andreu-Lara, Ojeda-Rivera, Villa \& Villa, 2017). Porque las visiones parciales son las que nutren al paisaje y ayudan a aproximarse a él para explicarlo y comprenderlo, pero no se puede perder de vista que la suma de estas especificidades no es igual al todo, sino que se integran en él como un conjunto más amplio y sorpresivo.

En definitiva, la tarea de redefinir el paisaje a partir de esta carga de informaciones, conduce por los caminos de la "hibridación" (Ábalos, 2007, pp. 91-92) y de la asociación de lo humano y lo no humano. Augustin Berque (1990) propone el concepto de "medianza" para dar cuenta de esta entidad relacional o medial que es el paisaje - a la vez totalmente natural y totalmente cultural-. Vincent Berdoulay (2002) habla de "copertenencia" entre sujeto perceptor y objeto percibido, de manera que el paisaje es a la vez objeto subjetivizado y sujeto objetivizado. El redescubierto geógrafo Eric Dardel acaba, en 1952, su libro sobre la naturaleza de la realidad geográfica con la siguiente frase: "La vida se encarga, a pesar de todas nuestras barreras intelectuales y de todas las precauciones de un positivismo corto de vista, de restituir a los espacios terrestres su frescor y su gloria, por poco que sepamos aceptarlos como don" (Dardel, 2013, p. 170). En el fondo, estamos retomando hoy el sentido original taoista de del shen-sui como "entidad relacional o trayectiva" y el llamado "principio de Zong Bing": "El paisaje, aunque es material, tiende al espíritu" (citado por Berque, 2009).

Agradecimientos: El trabajo se enmarca en las siguientes investigaciones: la tesis doctoral "Paisaje y calidad visual. Percepciones formales y sociales de paisajes singulares de la Sierra de Huelva", cuya doctoranda y director son los autores que firman el presente texto; el Proyecto de Excelencia "Archivo Documental de Percepciones y Representaciones de Paisajes Andaluces", financiado por Consejería de Economía, Innovación y Ciencia de la Junta de Andalucía (P09-HUM-5382); y el Proyecto "Las unidades básicas de paisaje agrario en España: identificación, caracterización y valoración. La España meridional andaluza", financiado por el Ministerio Español de Ciencia e Innovación (modalidad Proyectos I+D CSO2009-12225-C05-05).

Declaración responsable: Las/os autoras/es declaran que no existe ningún conflicto de interés en relación a la publicación de este artículo. Asimismo, ambas/os autoras/es han realizado conjuntamente las labores de búsqueda de documentación, análisis, reflexión y redacción del artículo. 


\section{Bibliografía}

Ábalos, I. (2007). Hibridación. In D. Colafranceschi (Ed.), Landsacape + 100 palabras para habitarlo (pp. 70-71). Barcelona: Gustavo Gili S.L.

Andersson, S. L. (2007). Ética. In D. Colafranceschi (Ed.), Landsacape + 100 palabras para habitarlo (pp. 70-71). Barcelona: Gustavo Gili S.L.

Arias, P. (2003). Periferias y Nueva Ciudad. El problema del paisaje en los procesos de dispersión urbana. Sevilla: Departamento de Urbanística y Ordenación del Territorio, Universidad de Sevilla.

Andreu-Lara, C., Ojeda-Rivera, J. F., Villa, A. A., \& Villa, J. (2017). El decurso del agua. Diálogo humanista ante paisajes de las marismas del Guadalquivir. Treballs de la Societat Catalana de Geografía, 84, 201-218. Retrieved from http://revistes.iec.cat/index.php/TSCG

Batlle, E. (2011). El jardín de la metrópoli. Del paisaje romántico al espacio libre para una ciudad sostenible. Barcelona: Gustavo Gili S.L.

Berdoulay, V. (2002). Sujeto y acción en la geografía cultural: el cambio sin concluir. Boletín de la Asociación de Geógrafos Españoles, 34, 51-61. Retrieved from http://www.agegeografia.es/ojs/index.php/bage/article/viewFile/427/398

Berque, A. (1990). Médiance. De milieux en paysages. Montpellier: GIP Reclus.

Berque, A., Conan, M., Donadieu, P., Lassus, B., \& Roger. A. (1994). Cinq propositions pour une théorie du paysage. Seyssel: Éditions Champ Vallon.

Berque, A. (1997). En el origen del paisaje. Revista de Occidente, 189, 7-21.

Berque, A. (2006). Cosmofanía y paisaje moderno. In J. Maderuelo (Dir.), Paisaje y pensamiento (pp. 187-207). Madrid: Fundación Beulas CDAN, Abada Editores S.L.

Berque, A. (2007). Cosmofanía. In D. Colafranceschi (Ed.), Landsacape + 100 palabras para habitarlo (pp. 70-71). Barcelona: Gustavo Gili S.L.

Berque, A. (2009). El pensamiento paisajero (ed. by J. Maderuelo). Madrid: Biblioteca Nueva S.L.

Bertrand, G. (1978). Le paysage entre la Nature et la Société. Revue Géographique des Pyrénées et du Sud-ouest, 49(2), 239-258. doi: http://dx.doi.org/10.3406/rgpso.1978.3552

Besse, J. (2006). Las cinco puertas del paisaje. Ensayo de una cartografía de las problemáticas paisajeras contemporáneas. In J. Maderuelo (Dir.), Paisaje y pensamiento (pp. 145-171). Madrid: Fundación Beulas CDAN, Abada Editores S.L.

Bolós, M. (1992). Manual de Ciencia del Paisaje. Teoría, métodos y aplicaciones. Barcelona: Masson S.A. 
Bonin, S. (2002). Paroles d’habitatns, discours sur les payages: des modèles aux territoires. L'évaluation des paysages du Fleuve Loire du Gerbier-de-Jonc à Nantes (Doctoral dissertation, Laboratoire Ladyss/Cnrs, Université de Paris I, Paris, France). Retrieved from https://journals.openedition.org/strates/439

Brinckerhoff, J. (2010). Descubriendo el paisaje autóctono. (ed. by J. Nogué). Madrid: Biblioteca Nueva S.L.

Cano, N. (2011). Miradas y tensiones de los paisajes del Valle de Carranza (Doctoral dissertation, Universidad del País Vasco, Spain). Retrieved from http://hdl.handle.net/10810/12197

Careri, F. (2002). Walkscapes. El andar como práctica estética. Barcelona: Gustavo Gili S.L.

Dardel, E. (2013) [1952]. El Hombre y la Tierra. Naturaleza de la realidad geográfica. Madrid: Biblioteca Nueva.

De la Fuente-De Val, G. J. (2004). Preferencias paisajísticas: un factor relevante para la gestión y conservación del paisaje de Chile Central. Ambiente y Desarrollo, XX(2), 12-26. Retrieved from http://www.cipmachile.com/web/200.75.6.169/RAD/2004/2de\%20la\%20Fuente.pdf

Español, I. (2002). El paisaje en los sistemas de ordenación territorial: revisión y base de una propuesta. Ordenación del Territorio, 60, 102-111. Retrieved from http://www.ciccp.es/revistait/buscador/index.html

Galí, T. (2007). Tiempo. In D. Colafranceschi (Ed.), Landsacape + 100 palabras para habitarlo (pp. 70-71). Barcelona: Gustavo Gili S.L.

Gámir, A. (2012). La consideración del espacio geográfico y el paisaje en el cine. Scripta Nova, XVI(403). Retrieved from http://www.ub.edu/geocrit/sn/sn-403.htm

García García, A., Ojeda-Rivera, J. F., \& Torres, F. J. (2008). Hacia una nueva lectura de la ciudad y sus espacios: ausencias y emergencias en la ciudad inteligente. In A. García García (Coord.), Espacio público, ciudad y conjuntos históricos (pp. 148-165). Sevilla: Instituto Andaluz de Patrimonio Histórico.

Gómez Orea, D. (1994). El paisaje como recurso socioeconómico. In II Congreso de Ciencia del Paisaje "Paisaje y Medio Ambiente" (pp. 33-43). Barcelona: Servei Científico-Tècnic de Gestió i Evolució del Paisatge.

Gómez Sal, A. (2006). La naturaleza en el paisaje. . In J. Maderuelo (Dir.), Paisaje y pensamiento (pp. 83-106). Madrid: Fundación Beulas CDAN, Abada Editores S.L.

González Bernáldez, F. (1981). Ecología y paisaje. Madrid: Blume.

Lassus, B. (2007). Heteródito. In D. Colafranceschi (Ed.), Landsacape + 100 palabras para habitarlo (pp. 70-71). Barcelona: Gustavo Gili S.L. 
Llorens, N. (2006). La creación artística y las visiones cambiantes del paisaje. In R. Mata, \& A. Tarroja (Coords.), El paisaje y la gestión sostenible del territorio (pp. 113-132). Barcelona: Diputació de Barcelona.

Lopez Gómez, C. (2016). Pasear Sevilla. El espíritu del jardín. Doce itinerarios para sentir la ciudad a través de sus jardines. Sevilla: Entorno Gráfico Ediciones.

Luginbühl, Y. (2012). La mise en scène du monde. Construction du paysage européen. Paris: CNRS editions.

Margalef, R. (1974). Ecología. Barcelona: ed. Omega.

Mata, R. (2006). Un concepto de paisaje para la gestión sostenible del territorio. In R. Mata, \& A. Tarroja (Coords.), El paisaje y la gestión sostenible del territorio (pp. 17-40). Barcelona: Diputació de Barcelona.

MECD (2017). Plan Nacional de Paisaje Cultural. In Ministerio de Educación Cultura y Deporte. Retrieved from http://www.mecd.gob.es/planes-nacionales/planes-nacionales/paisaje-cultural.html Milani, R. (2006). Estética del paisaje: formas, cánones, intencionalidad. In J. Maderuelo (Dir.), Paisaje y pensamiento (pp. 55-82). Madrid: Fundación Beulas CDAN, Abada Editores S.L.

Milani, R. (2007). El arte del paisaje. (Ed. by F. López Silvestre). Madrid: Biblioteca Nueva S.L.

Milani, R. (2008). Estética y crítica del paisaje. In J. Nogué (Ed.), El paisaje en la cultura contemporánea (pp. 45-66). Madrid: Biblioteca Nueva S.L.

Morin, E. (1996). Introducción al Pensamiento complejo. Madrid: Editorial Gedisa.

Nogué, J. (2007). Territorios sin discurso, paisajes sin imaginario. Retos y dilemas. Ería, 73-74, 373-382. Retrieved from

https://www.unioviedo.es/reunido/index.php/RCG/article/view/1593/15038

Nogué, J. (2008). Introducción. La valoración cultural del paisaje en la contemporaneidad. In J. Nogué (Ed.), El paisaje en la cultura contemporánea (pp. 9-24). Madrid: Biblioteca Nueva S.L.

Ortega Cantero, N. (1988). Geografía y Cultura. Madrid: Alianza Editorial.

Ortega Cantero, N. (2006). Entre la explicación y la comprensión: el concepto de paisaje en la geografía moderna. In J. Maderuelo (Dir.), Paisaje y pensamiento (pp. 107-130). Madrid: Fundación Beulas CDAN, Abada Editores S.L.

Ortega Cantero, N. (2007). La valoración patrimonial y simbólica del paisaje de Castilla (18751936). Ería, 73-74, 137-159. Retrieved from

https://www.unioviedo.es/reunido/index.php/RCG/article/view/1580 
Priore, R. (2002). Derecho al paisaje, derecho del paisaje. In F. Zoido, \& C. Venegas (Coords.), Paisaje y ordenación del territorio (pp. 92-99). Sevilla: Junta de Andalucía.

Rivasplata, P. E. (2011). Legado precolombino peruano a la construcción de paisajes andinos. Identificación, construcción, representación y simbolización de paisajes precolombinos. Madrid: Editorial Académica Española (EAE).

Roger, A. (2007). Breve tratado del paisaje. (Ed. by J. Maderuelo). Madrid: Biblioteca Nueva S.L. Roger, A. (2008). Vida y muerte de los paisajes. Valores estéticos, valores ecológicos. In J. Nogué (Ed.), El paisaje en la cultura contemporánea (pp. 67-86). Madrid: Biblioteca Nueva S.L.

Silva, R., \& Fernández, V. (2017). El nuevo paradigma del patrimonio y su consideración con los paisajes. Conceptos, métodos y prospectivas. Documents d'anàlisi geográfica, 63(1), 129-151. doi: http://dx.doi.org/10.5565/rev/dag.344

Tort, J. (2006). Del pagus al paisaje: cinco apuntes y una reflexión. In R. Mata, \& A. Tarroja (Coords.), El paisaje y la gestión sostenible del territorio (pp. 699-712). Barcelona: Diputació de Barcelona.

Troll, C. (1950). Die geographisched Landscahaft und ihre Erforschung. Studium Generale, 3, $163-81$.

Truax, B. (1994). The inner and outer complexity of music. Perspectives of New Music, 32, 176193.

Truax, B. (2001). Soundscape Composition as Global Music. Paper presented at the Sound Escape Conference, Trent University, Ontario, Canada.

Turri, E. (1998). II paesaggio come teatro.Dal territorio vissuto al territorio rappresentato. Venezia: Marsilio.

Venturi, M. (2007). Éstética. In D. Colafranceschi (Ed.), Landsacape + 100 palabras para habitarlo (pp. 70-71). Barcelona: Gustavo Gili S.L.

Watsuji, T. (2006). Antropología del paisaje: climas, culturas y religiones. Salamanca: Ediciones Sigueme.

Wylie, J. (2007). Landscape. Abingdon: Routledge.

Zimmer, J. (2008). La dimensión ética de la estética del paisaje. In R. Mata, \& A. Tarroja (Coords.), El paisaje y la gestión sostenible del territorio (pp. 27-44). Barcelona: Diputació de Barcelona.

Zoido, F. (2000). Proteger y realzar el paisaje. Andalucía Geográfica, 7, 7-14. doi: http://dx.doi.org/10.5565/rev/dag.344 
Zoido, F. (2002). El paisaje y su utilidad para la Ordenación del Territorio. In F. Zoido, \& C. Venegas (Coords.), Paisaje y ordenación del territorio (pp. 21-32). Sevilla: Junta de Andalucía. 